\title{
Surgical Outcomes of Laparoscopic Versus Open Abdominoperineal Resection for Anorectal Cancer: A Comparative Study
}

\author{
Masafumi Inomata $^{1 *}$, Kentaro Nakajima1, Yohei Kono ${ }^{1}$, Takahiro Hiratsuka $^{1}$ Takuro Futsukaichi $^{1}$, Shigeo Ninomiya ${ }^{1}$, Norio Shiraishi ${ }^{2}$ and $^{1}$ \\ Seigo Kitano ${ }^{3}$ \\ ${ }^{1}$ Department of Gastroenterological and Pediatric Surgery, Oita University Faculty of Medicine, Oita, Japan \\ ${ }^{2}$ Center for Community Medicine, Oita UniversityFaculty of Medicine, Oita, Japan
}

${ }^{3}$ Oita University, Oita, Japan

\begin{abstract}
Introduction: There has been no large, randomized prospective trial and few retrospective studies to clarify the surgical outcomes of laparoscopic abdominoperineal resection (Lap-APR) for anorectal cancer. The aim of this study was to clarify the surgical outcomes of Lap-APR for anorectal cancer.

Methods: A consecutive series of 39 patients who underwent abdominoperineal resection for anorectal cancer was studied: 24 underwent Lap-APR, and 15 open abdominoperineal resection (Open-APR). Patient characteristics, tumor characteristics and operative outcomes were compared between the groups.

Results: There were no significant differences between the groups in patient and tumor characteristics. The mean number of harvested nodes in the Lap-APR group was significantly more than that in the Open-APR group (11.8 \pm 8.7 vs.7.6 $\pm 3.6, p=0.046)$. Although the mean operation time was similar in the two groups $(372.1 \pm 79.0$ vs.402.7 \pm 118.4 min, N.S), the mean blood loss in the Lap-APR group was significantly less than that in the Open-APR group (244.6 \pm 175.0 vs. $795.3 \pm 544.9 \mathrm{~g}, \mathrm{p}=0.002$ ). Additionally, time to start oral intake of solid foods and time to first education of stoma management were significantly less after Lap-APR than Open-APR.
\end{abstract}

Conclusion: Lap-APR offered particular advantages to patients with anorectal cancer,including less blood loss, rapid oral intake of solid foods and education of stoma care.

Keywords: Laparoscopic abdominoperineal resection; Anorectal cancer; Stoma management

\section{Introduction}

The incidence of colorectal cancer in Japan in increasing [1], and the change to a more westernized diet, characterized by a high intake of fat and meat, is known to be related to these increases [2]. According to the Japanese Society for Cancer of the Colon and Rectum (JSCCR), a total of 77520 patients, 405288 with colonic and 36992 with rectal cancer, were registered in the 20-year period 1974 to 1993 in Japan [3].

Laparoscopic surgery for colon disease has been widely adopted since it was first reported in 1990 [4] and is being used increasingly in Japan [5]. Laparoscopic surgery has been associated with less pain, quicker return of gastrointestinal function, better pulmonary function, decreased stress response, a shorter stay and better postoperative quality of life (QoL) than open surgery [6]. In addition, recent large randomized trial comparing laparoscopic with open surgery for colon cancer have reported that laparoscopic surgery for colon cancer is equivalent to open surgery in terms of long-term outcomes [7-10]. However, there has been no large, randomized prospective trial and few retrospective studies to clarify the surgical outcomes of Laparoscopic abdominoperineal resection (Lap-APR) for anorectal cancer. The aim of this study was to clarify the surgical outcomes and benefits of LapAPR for anorectal cancer.

\section{Patients and Methods}

Between 2002 and 2012, 39 patients with anorectal cancer underwent APR at the department of Gastroenterological Surgery, Oita University. This retrospective study included 39 consecutive patients with anorectal cancer. Patients with bulky tumors, those with a history of extensive adhesion, ulcerative colitis and those with multiple cancers, and distant metastasis were excluded in this study. Of the 39 patients, 24 underwent Lap-APR and 15 underwent open abdominoperineal resection (Open-APR). All patients underwent preoperative colonoscopy, barium study and radiographic study. When the authors introduced Lap-APR in 2002, only T1/T2 tumors in the lower rectum were targeted. In 2006, the indications for it have expanded T1-T3 tumors in our institution. We did not perform any emergency APR during this period. Neoadjuvant chemoradiotherapy was performed in patients with clinical T3 or T4 tumors.

Surgical technique of Lap-APR: Our Lap-APR was performed according to Pugliese et al. [11]. In brief, the patient was placed in a modified lithotomy position. Pneumoperitoneum was created by the open technique using Hasson trocar inserted above the umbilicus. Four working trocars were inserted under direct vision. The sigmoid colon and rectum were mobilized from the pelvic floor using medial and lateralapproach. The inferior mesenteric artery was clipped and divided at $1.5 \mathrm{~cm}$ from its origin preserving the hypogastric nerve. After the rectum with the mesorectum was completely mobilized according to the Total Mesorectal Excision (TME) rule [12], sigmoid colon was transected with linear stapler. The specimen was removed through the perineal wound. A terminal colostomy using sigmoid colon was fashioned at the left lower trocar site. Lateral dissections were not performed for all cases.

${ }^{*}$ Corresponding author: Masafumi Inomata, Department of Gastroenterologica and Pediatric Surgery, Oita University Faculty of Medicine, 1-1 Idaigaoka, Yufu, Oita 879-5593, Japan, Tel: 81-97-586-5843; Fax: 81-97-549-6039; E-mail: inomata@oita-u.ac.jp

Received January 15, 2014; Accepted February 05, 2014; Published February 12,2014

Citation: Inomata M, Nakajima K, Kono Y, Hiratsuka T, Futsukaichi T, et al. (2014) Surgical Outcomes of Laparoscopic Versus Open Abdominoperinea Resection for Anorectal Cancer: A Comparative Study. Surgery Curr Res 4: 175 doi:10.4172/2161-1076.1000175

Copyright: (c) 2014 Inomata M, et al. This is an open-access article distributed under the terms of the Creative Commons Attribution License, which permits unrestricted use, distribution, and reproduction in any medium, provided the original author and source are credited. 
Stomal care: After operation the stomas of all patients were cared by trained stomal nurses in our university surgical unit. Patients were discharged from hospital when a nurse was satisfied that the patient could fit a new appliance, could change a pouch without leakage, and could deal with minor accidents such as stomal leakage, skin excoriation, and excessive gas in the stomal pouch.

Patient characteristics, tumor characteristics and operative outcomes were compared between groups. These data were obtained from medical charts, operation records and pathology reports. Pathologic findings were based on the $6^{\text {th }}$ TNM classification [13]. The median follow-up period was 43 months (range 3-109 months).

The results were expressed as mean \pm standard deviation (SD). The Fisher's exact test was used to compare categorical variables and the $t$ test for continuous variables. A $p$-value $<0.05$ was considered statistically significant.

\section{Results}

In the Lap-APR group, no conversion to open surgery was required. Table 1 shows the patients characteristics enrolled in this study. Although there were no significant differences between groups in patient age, gender, incidence of previous surgery and body mass index, patients treated with preoperative chemoradiotherapy(CRT) in Lap-APR group were significantly more than those in Open-APR group ( 20.8 vs. $60 \%, \mathrm{p}=0.013)$. Tumor characteristics were also shown in Table 2. Posttreatment clinical TNM stage is shown for patients treated with preoperative CRT. There were no significant differences between groups in tumor location, histologic type, depth of tumor invasion (T), nodal involvement $(\mathrm{N})$, and stage. The mean number of harvested nodes in the Lap-APR group was significantly more than that in the Open-APR group $(11.8 \pm 8.7$ vs. $7.6 \pm 3.6, \mathrm{p}=0.046)$.

The operative outcomes were shown in Table 3. Although the mean operation time was similar in the two groups $(372.1 \pm 79.0$ vs. $402.7 \pm 118.4 \mathrm{~min}$, N.S), the mean blood loss in the Lap-APR group was significantly less than that in the Open-APR group (244.6 \pm 175.0 vs. $795.3 \pm 544.9 \mathrm{~g}, \mathrm{p}=0.002)$. The postoperative complication rate was similar in the two groups ( 33.3 vs. $40.0 \%$, NS). Although the time to first passageof flatus and length of postoperative hospital stay were similar in the two groups, time to start oral intake of solid foods and fist education of stoma management were significantly less after LapAPR than Open-APR. In addition, the rate of tumor recurrence was also similar in the two groups.

\section{Discussion}

Several studies have shown favorable surgical outcomes of laparoscopic surgery, In particular, laparoscopic surgery has been characterized by less blood loss in gastric [6] and colorectal cancer surgery [14]. Our study also showed the mean blood loss in the Lap-

\begin{tabular}{|l|c|c|c|}
\hline & Lap-APR $(n=24)$ & Open-APR $(n=15)$ & P value \\
\hline Age $(\mathrm{y})$ & $69.2 \pm 17.7$ & $61.5 \pm 10.6$ & N.S. \\
\hline Gender (M/F) & $15 / 9$ & $12 / 3$ & N.S. \\
\hline $\begin{array}{l}\text { Previous surgery } \\
\text { (Present/ Absent) }\end{array}$ & $9 / 15$ & $5 / 10$ & N.S. \\
\hline BMI & $21.3 \pm 4.00$ & $22.7 \pm 4.4$ & N.S. \\
\hline $\begin{array}{l}\text { Preoperative } \\
\text { CRT }\end{array}$ & $5(20.8 \%)$ & $9(60 \%)$ & 0.013 \\
\hline
\end{tabular}

Mean \pm SD

BMI, Body mass index

Table 1: Patients characteristics.

\begin{tabular}{|c|c|c|c|}
\hline & LapAPR $(n=24)$ & Open-APR $(n=15)$ & $P$ value \\
\hline Location & $23 / 1$ & $15 / 0$ & N.S \\
\hline \multicolumn{4}{|l|}{ (Rectum/ Anus) } \\
\hline Histologic type & $7 / 14 / 3$ & $4 / 11 / 0$ & N.S \\
\hline \multicolumn{4}{|l|}{ (well/mod/other) } \\
\hline $\mathrm{T}$ & & & N.S \\
\hline $\mathrm{T} 1$ & 6 & 0 & \\
\hline $\mathrm{T} 2$ & 6 & 5 & \\
\hline T3 & 12 & 9 & \\
\hline $\mathrm{T} 4$ & 0 & 1 & \\
\hline$N$ & & & N.S \\
\hline No & 18 & 10 & \\
\hline N1 & 5 & 5 & \\
\hline N2 & 1 & 0 & \\
\hline Stage & & & N.S \\
\hline I & 10 & 4 & \\
\hline II & 8 & 6 & \\
\hline III a & 5 & 5 & \\
\hline III $b$ & 1 & 0 & \\
\hline Harvested nodes & $11.8 \pm 8.7$ & $7.6 \pm 3.6$ & 0.046 \\
\hline (n) & & & \\
\hline
\end{tabular}

Mean \pm SD

Table 2: Tumor characteristics.

\begin{tabular}{|l|c|c|c|}
\hline & LapAPR $(\mathrm{n}=24)$ & Open-APR $(\mathrm{n}=15)$ & P value \\
\hline Operation time (min) & $372.1 \pm 79.0$ & $402.7 \pm 118.4$ & N.S \\
\hline Blood loss (g) & $244.6 \pm 175.0$ & $795.3 \pm 544.9$ & 0.002 \\
\hline Complication & $8(33.3 \%)$ & $6(40.0 \%)$ & N.S \\
\hline $\begin{array}{l}\text { Time to first passage of flatus } \\
\text { (days) }\end{array}$ & $2.4 \pm 1.5$ & $3 \pm 1.3$ & N.S \\
\hline $\begin{array}{l}\text { Time to start oral intake of solid } \\
\text { foods (days) }\end{array}$ & $2.7 \pm 1.1$ & $4.5 \pm 3.2$ & 0.013 \\
\hline $\begin{array}{l}\text { Time to first education of stoma } \\
\text { management (days) }\end{array}$ & $6.1 \pm 2.5$ & $8.3 \pm 3.4$ & 0.031 \\
\hline $\begin{array}{l}\text { Postoperative hospital stay } \\
\text { (days) }\end{array}$ & $31.2 \pm 24.0$ & $38.9 \pm 20.0$ & N.S. \\
\hline Recurrence & $7(29 \%)$ & $10(67 \%)$ & N.S \\
\hline
\end{tabular}

Mean \pm SD

Table 3: Operative outcomes.

APR group was less than that in the Open-APR group. Because the perineal approach in the both groups remains unchanged, we believed that radical lymph node dissection and pelvic dissection in the narrow pelvic floor were archived with proper homeostasis by well visualization in the Lap-APR group.

Also, laparoscopic surgery has been reported as a procedure with longer operation time when compared with conventional open surgery. However, our study showed that there were no significant differences between groups with respect to the mean operation time. We believed that one of the reasons why the mean operation time was not significant was Lap-APR was characterized by a permanent stoma and perineal procedure as well as Open-APR and the other was that Lap-APR could be avoided closure of the midline laparotomy wound. Wong et al. [15] also reported that the median operation time in the Lap-APR was similar when compared with that in the Open-APR group in their non- 
randomized prospective comparative study. Randomized control study to clarify the operation time is necessary.

Although this study did not reveal significant shortening the length of hospital stay in Lap-APR, most studies have reported that the hospital stay in the laparoscopic surgery for rectal cancer was shorter when compared with the conventional open surgery group [14,16,17]. Lap-APR was characterized by a permanent stoma and perineal wound as well as Open-APR. The patients in the Lap-APR group avoided a large abdominal wound which seemed to provide the earlier recovery. In addition, our results also showed that the patients who underwent Lap-APR could be educated and achieve in managing their stoma earlier because of no abdominal incision except trocar sites and stoma. Although length of postoperative hospital stay was not significantly different between groups, we believe that the patients undergoing LapAPR without a large abdominal wound can manage their stoma easier than those undergoing Open-APR. To our knowledge, our study was first to clarify the benefit of Lap-APR in terms of stoma care.

Some surgeons have believed that patients who have a colostomy have a worse QoL than that without stoma. Therefore, they have indicated sphincter-preserving surgery for the patients with lower rectal cancer to avoid a permanent stoma. However, Cornish et al. [18] reported that the patients undergoing APR did not have a worse QoL than patients undergoing anterior resection problems, such as continence and controlling their stools, influenced on the worse QoL following anterior resection. Lap-APR without large abdominal wound may provide the better-stoma related QoL only related stoma care in patients who underwent Lap-APR is necessary.

Limitations of this study were retrospective, and that the study group was not randomized. Therefore, selection bias might have existed because the patients treated with preoperative CRT were less in Lap-APR group than Open-APR group. Although it is possible that preoperative CRT for rectal cancer could influence the surgical outcome, a prospective randomized trial, the comparison of open versus laparoscopic surgery for mid and low rectal cancer after neoadjuvant chemoradiotherapy (COREAN trial), reported the safety and shortterm advantages including less blood loss and earlier recovery of bowel function in laparoscopic surgery for rectal cancer after preoperative CRT [19]. Lap-APR was also performed safety without any severe intraoperative complication in five cases with preoperative CRT in this study. We believe short- termadvantages in Lap-APR group was not because of the bias of preoperative CRT, but because they were performed "laparoscopic operation".

To date, some studies have clarified the long-term results of Phase III randomized trial of laparoscopic surgery for colon cancer [7-10]. According to these studies, laparoscopic surgery has been accepted as a standard treatment for colon cancer. However, there has been no large, randomized, prospective trial to compare open and laparoscopic APR for anorectalcancer. Fleshman et al. [16] reported that there were no significant differences between both groups in overall diseasefree survival rates in their 194 cases retrospective comparative study. Pugliese et al. [11] reported that 5-year survival rate of 32 cases undergoing Lap-APR for rectal cancer was 0.5 in their case series. However, a randomized, prospective trial is necessary to clarify the long-term outcomes of Lap-APR for anorectal cancer.

In conclusion, Lap-APR offered particular advantages to patients with anorectal cancer, including less blood loss, rapid oral intake of solid foods and education of stoma care.

\section{Acknowledgments}

The authors do not have any conflicts of interest or financial ties to disclose.

\section{References}

1. Kono S (2004) Secular trend of colon cancer incidence and mortality in relation to fat and meat intake in Japan. Eur J Cancer Prev 13: 127-132.

2. Lee SI, Moon HY, Kwak JM, Kim J, Min BW, et al. (2008) Relationship between meat and cereal consumption and colorectal cancer in Korea and Japan. J Gastroenterol Hepatol 23: 138-140

3. Muto T, Kotake K, Koyama Y (2001) Colorectal cancer statistics in Japan: data from JSCCR registration, 1974-1993. Int J Clin Oncol 6: 171-176.

4. Jacobs M, Verdeja JC, Goldstein HS (1991) Minimally invasive colon resection (laparoscopic colectomy). Surg Laparosc Endosc 1: 144-150.

5. Ohta M, Kitano S, Kasama K, Kawamura I, Inamine S, et al. (2011) Results of a national survey on laparoscopic bariatric surgery in Japan, 2000-2009. Asian $\mathrm{J}$ Endosc Surg 4: 138-142.

6. Yasuda K, Sonoda K, Shiroshita H, Inomata M, Shiraishi N, et al. (2004) Laparoscopically assisted distal gastrectomy for early gastric cancer in the elderly. Br J Surg 91: 1061-1065.

7. Lacy AM, García-Valdecasas JC, Delgado S, Castells A, Taurá P, et al. (2002) Laparoscopy-assisted colectomy versus open colectomy for treatment of nonmetastatic colon cancer: a randomised trial. Lancet 359: 2224-2229.

8. Laparoscopically assisted colectomy is as safe and effective as open colectomy in people with colon cancer Abstracted from: Nelson H, Sargent D, Wieand HS, et al; for the Clinical Outcomes of Surgical Therapy Study Group. A comparison of laparoscopically assisted and open colectomy for colon cancer. N Engl J Med 2004; 350: 2050-2059. Cancer Treat Rev 30: 707-709.

9. Guillow PJ, Quirke P, Thorpe H (2005) MRC CLASICC trial group. Short-term endopoints of conventional versus laparoscopic-assisted surgery in patients with colorectal cancer (MRC CLASICC trial): multicentre, randomized controlled trial. Lancet 365:1718-1726.

10. Jayne DG, Guillou PJ, Thorpe H, Quirke P, Copeland J, et al. (2007) Randomized trial of laparoscopic-assisted resection of colorectal carcinoma: 3-year results of the UK MRC CLASICC Trial Group. J Clin Oncol 25: 3061 3068.

11. Pugliese R, Di Lernia S, Sansonna F, Ferrari GC, Maggioni D, et al. (2007) Outcomes of laparoscopic Miles' operation in very low rectal adenocarcinoma. Analysis of 32 cases. Eur J Surg Oncol 33: 49-54.

12. Heald RJ, Husband EM, Ryall RD (1982) The mesorectum in rectal cance surgery--the clue to pelvic recurrence? Br J Surg 69: 613-616.

13. Greene FL, Page DL, Fleming ID (2002) AJCC Cancer Staging manual ( $6^{\text {th }}$ edn). New York: Spriner-Verlag.

14. Leung KL, Kwok SP, Lau WY, Meng WC, Chung CC, et al. (2000) Laparoscopicassisted abdominoperineal resection for low rectal adenocarcinoma. Surg Endosc 14: 67-70

15. Wong DC, Chung CC, Chan ES, Kwok AS, Tsang WW, et al. (2006) Laparoscopic abdominoperineal resection revisited: are there any healthrelated benefits? A comparative study. Tech Coloproctol 10: 37-42.

16. Fleshman JW, Wexner SD, Anvari M, La Tulippe JF, Birnbaum EH, et al. (1999) Laparoscopic vs. open abdominoperineal resection for cancer. Dis Colon Rectum 42: 930-939.

17. Aziz O Constantinides $\mathrm{V}$, Tekkis PP, Athanasiou T, Purkayastha $S$, et al. (2006) Laparoscopic versus open surgery for rectal cancer: a meta-analysis. Ann Surg Oncol 13: 413-424

18. Cornish JA, Tilney HS, Heriot AG, Lavery IC, Fazio VW, et al. (2007) A metaanalysis of quality of life for abdominoperineal excision of rectum versus anterior resection for rectal cancer. Ann Surg Oncol 14: 2056-2068.

19. Kang SB, Park JW, Jeong SY (2011) Open versus laparoscopic surgery for mid and low rectal cancer after neoadjuvant chemoradiotherapy (COREAN trial) short-term outcomes of an open-label randomised controlled trial. Lancet Onco 11: $637-645$ 